\section{Evaluation of the ulnar nerve with shear-wave elastography: a potential sonographic method for the diagnosis of ulnar neuropathy}

\author{
Sujin Kim, Guen Young Lee \\ Department of Radiology, Chung-Ang University Hospital, Seoul, Korea
}

Purpose: This study was designed to verify whether shear-wave elastography (SWE) can be used to differentiate ulnar neuropathy at the cubital tunnel from asymptomatic ulnar nerve or medial epicondylitis. An additional aim was to determine a cut-off value to identify patients with ulnar neuropathy.

Methods: This study included 10 patients with ulnar neuropathy at the cubital tunnel as confirmed with electromyography (three women and seven men; mean age, 51.9 years), 10 patients with medial epicondylitis (nine women and one man; mean age, 56.1 years), and 37 patients with asymptomatic ulnar nerve and lateral epicondylitis (21 women and 16 men; mean age, 54.0 years). Each patient underwent SWE of the ulnar nerve at the cubital tunnel, distal upper arm, and proximal forearm.

Results: Patients with ulnar neuropathy at the cubital tunnel exhibited significantly greater mean ulnar nerve stiffness at the cubital tunnel $(66.8 \mathrm{kPa})$ than controls with medial epicondylitis (21.2 kPa, $\mathrm{P}=0.015)$ or lateral epicondylitis $(33.9 \mathrm{kPa}, \mathrm{P}=0.040)$. No significant differences were observed between patients and controls with regard to ulnar nerve stiffness at the distal upper arm or the proximal forearm. A stiffness of $31.0 \mathrm{kPa}$ provided $100 \%$ specificity, $80.0 \%$ sensitivity, $100 \%$ positive predictive value, and $83.3 \%$ negative predictive value for the differentiation between ulnar neuropathy and medial epicondylitis.

Conclusion: Cubital tunnel syndrome is associated with a stiffer ulnar nerve than lateral or medial epicondylitis. SWE seems to be a new, reliable, and simple quantitative diagnostic technique to aid in the precise diagnosis of ulnar neuropathy at the cubital tunnel.

Keywords: Ulnar neuropathy; Cubital tunnel syndrome; Medial epicondyle pain;

Shear-wave elastography

\section{Introduction}

Cubital tunnel syndrome is a common nerve entrapment syndrome of the upper extremity that is caused by compression of the ulnar nerve at the cubital tunnel of the elbow [1]. This condition has a broad symptom complex of sensory and motor deficiencies and dysesthesia [2,3]. Cubital tunnel
ULTRA

SONO

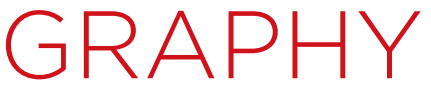

ORIGINAL ARTICLE

https://doi.org/10.14366/usg.20101 pISSN: 2288-5919 • elSSN: 2288-5943

Ultrasonography 2021;40:349-356

Received: July 3, 2020

Revised: August 23, 2020

Accepted: August 23, 2020

Correspondence to:

Guen Young Lee, MD, Department of Radiology, Chung-Ang University Hospital, 102 Heukseok-ro, Dongjakgu, Seoul 06973, Korea

Tel. +82-2-6299-2646

Fax. +82-2-6263-1557

E-mail: netty0523@gmail.com

This is an Open Access article distributed under the terms of the Creative Commons Attribution NonCommercial License (http://creativecommons.org/ licenses/by-nc/4.0/) which permits unrestricted noncommercial use, distribution, and reproduction in any medium, provided the original work is properly cited.

Copyright @ 2021 Korean Society of Ultrasound in Medicine (KSUM)

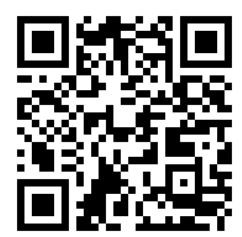

How to cite this article:

Kim S, Lee GY. Evaluation of the ulnar nerve with shear-wave elastography: a potential sonographic method for the diagnosis of ulnar neuropathy. Ultrasonography. 2021 Jul;40(3):349-356. 
syndrome is typically diagnosed using the clinical information gained from the patient's history as well as symptoms, physical examination, and electrodiagnostic studies [4]. However, because cubital tunnel syndrome has a variety of clinical characteristics, it is difficult to differentiate from other diseases that can affect the elbow joint based on clinical presentation and an electrodiagnostic study. Although an electrodiagnostic study is considered the most important diagnostic test for cubital tunnel syndrome, it has some critical disadvantages. It is time-consuming, causes pain and injury to patients due to needle insertion and electrical stimulation, provides limited information regarding lesion localization and structural abnormalities, and carries a strong possibility of falsenegative results [5]. Thus, complementary imaging studies such as magnetic resonance or ultrasound imaging are required for the diagnosis of various neuropathies. Ultrasound imaging in particular supports the diagnosis of neuropathy by providing superior spatial resolution of small peripheral nerves and detailed information regarding lesion localization [6]. Moreover, as a recently-developed ultrasound imaging technology, shear-wave elastography (SWE) has the potential to provide quantitative values for the soft tissue stiffness of tissues, including the muscle [7], tendon [8], joint capsule [9], benign soft tissue mass [10], and nerves, and to improve the diagnostic performance of ultrasound imaging for various neuropathies involving the median, sciatic, tibial, and ulnar nerves [11-15].

The aim of this study was to verify whether cubital tunnel syndrome can be diagnosed based on quantitative ulnar nerve stiffness data obtained with SWE, as well as to compare patients with ulnar neuropathy to those with medial epicondylitis and lateral epicondylitis to establish a precise cut-off value of this parameter for use in ultrasound imaging.

\section{Materials and Methods}

\section{Subjects}

Institutional review board approval was obtained (CAU IRB No. 1907-013-16575), and the requirement for informed consent was waived because of the retrospective nature of the study. Our study included a review of 77 consecutive patients who had elbow pain and underwent elbow ultrasonography at our institution between October 2018 and December 2018. Twenty patients were excluded due to the lack of an elastography image $(n=10)$, postoperative status $(n=2)$, or a low reliability measurement index (RMI) $(\mathrm{RMI} \leq 0.4)(n=8)$. Therefore, this study included 10 patients with ulnar neuropathy at the cubital tunnel as confirmed with electromyography (three women and seven men; mean age, $51.9 \pm 18.8$ years), 10 patients with medial epicondylitis (nine women and one man; mean age, $56.1 \pm 9.8$ years), and 37 patients with asymptomatic ulnar nerve and lateral epicondylitis (21 women and 16 men; mean age, $54.0 \pm 8.8$ years).

\section{Imaging Protocol}

All patients underwent B-mode ultrasound and SWE with a Samsung RS85 ultrasonography apparatus equipped with a 2-to 9-MHz linear transducer (Samsung Medison Co., Ltd., Seoul, Korea). Ultrasound imaging and SWE were performed concurrently by one of two radiologists with more than 10 years of experience in musculoskeletal radiology. The examining radiologist was blinded to the patient's clinical history and to the results of the physical examination and electrodiagnostic study. The examination was performed with the patient in a sitting position, facing the examiner. The arm to be examined, in the neutral position and with the elbow flexed at $30^{\circ}$, was placed comfortably on a cushion located on the patient's knee. To minimize the pressure on the skin surface, the probe was coated with sufficient hydrogel and placed on the examined area. During B-mode ultrasound examination of the elbow, the transducer was kept perpendicular to the ulnar nerve. The cross-sectional area (CSA) of the ulnar nerve was measured using a manual tracing measurement tool within the hyperechoic line that surrounds the ulnar nerve. This parameter was measured at three levels of the cubital tunnel: at the medial epicondyle, $4 \mathrm{~cm}$ proximal to the epicondyle, and $4 \mathrm{~cm}$ distal to the epicondyle. The echogenicity of the ulnar nerve at the cubital tunnel was assessed on a transverse B-mode image for the evaluation of ulnar nerve neuropathy. Ulnar nerve stiffness was measured at three levels along a longitudinal axis of the ulnar nerve: in the middle of the cubital tunnel at the level of the medial epicondyle, $4 \mathrm{~cm}$ proximal, and $4 \mathrm{~cm}$ distal to the cubital tunnel at the level of the medial epicondyle (i.e., on the distal upper arm and proximal forearm, respectively). The transducer was kept parallel to the skin surface, and special attention was paid to avoid direct compression of the ulnar nerve. In addition, the ulnar nerve was kept in the center of the selected square region of interest (ROI, $5 \mathrm{~mm}$ in diameter). Shear modulus data for the selected square ROI were acquired automatically by the ultrasonographic software. The nerve stiffness at each level was measured twice at an interval of 2-3 minutes, and the measurement with the higher RMI value was used as the nerve stiffness value. The results were expressed in kilopascals ( $\mathrm{kPa}$ ). Representative images of the control group, characterized by low values for nerve stiffness, are shown in Fig. 1.

\section{Statistical Analysis}

The normality of the distribution of the data associated with the study variables was verified with the Shapiro-Wilk test. The significance of intergroup differences in sex, the affected side, 


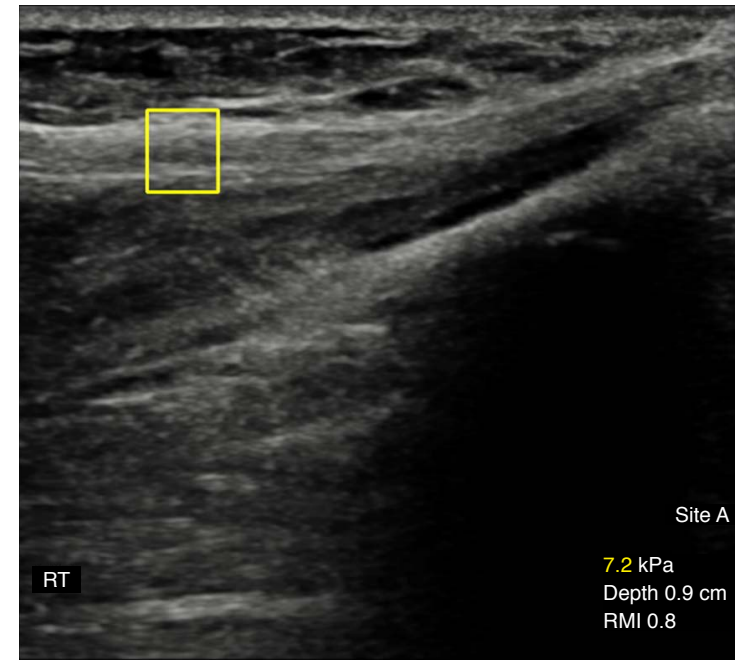

A

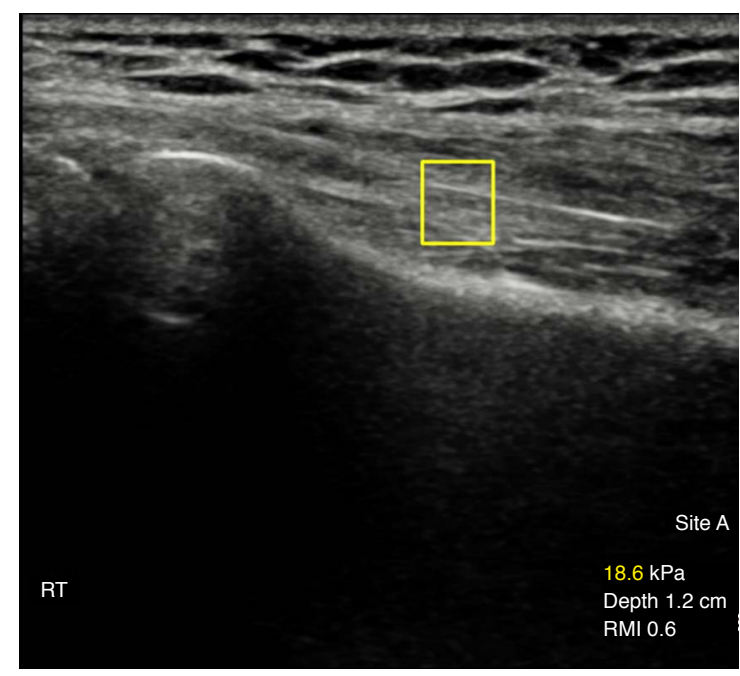

C

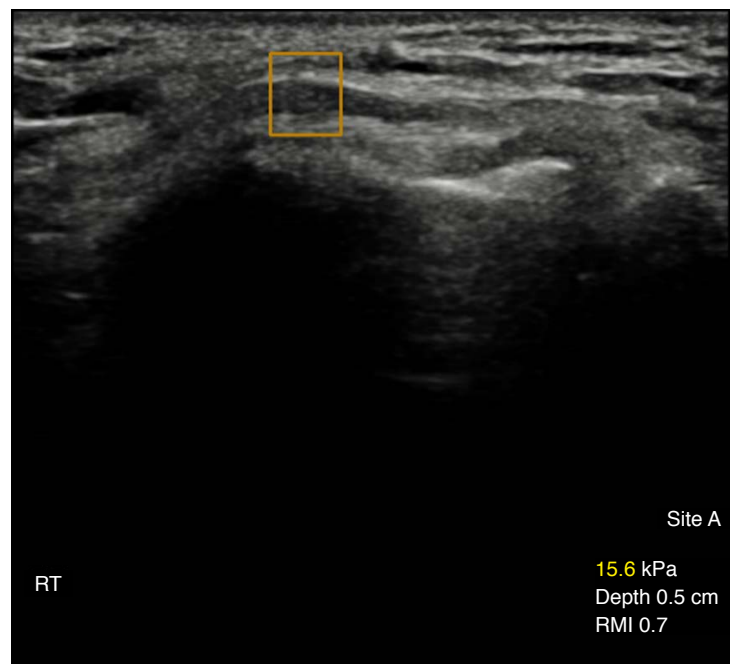

B
Fig. 1. A 58-year-old woman with right lateral epicondylitis.

Elastography images of the ulnar nerve at the elbow are shown. A. The shearwave elastography (SWE) value of the ulnar nerve at the level of the distal upper arm was $7.2 \mathrm{kPa}$. B. The SWE value of the ulnar nerve at the level of the cubital tunnel was $15.6 \mathrm{kPa}$. C. The SWE value of the ulnar nerve at the level of the proximal forearm was $18.6 \mathrm{kPa}$. RMI, reliability measurement index. and the echogenicity of the ulnar nerve at the cubital tunnel was analyzed with the Fisher exact test, and that of differences in the numerical characteristics of continuous variables was verified with the Kruskal-Wallis test with the Dunn post-hoc test, the t test, or the Mann-Whitney test. The relationship between CSA and SWE values was evaluated using the Pearson correlation coefficient. The diagnostic accuracy of ulnar nerve stiffness and CSA in the detection of ulnar neuropathy was verified using receiver operating characteristic (ROC) curve analysis. Sensitivity, specificity, and positive and negative predictive values (PPV and NPV, respectively) of each potential predictor of ulnar neuropathy were calculated, along with the area under the ROC curve (AUC) and the associated 95\% confidence intervals ( $\mathrm{Cls}$ ). All statistical analysis was performed with statistical software (SPSS version 25.0, IBM Corp., Armonk, NY, USA), with the threshold for statistical significance set at $P \leq 0.05$.

\section{Results}

The demographic information of the patients is summarized in Table 1. The results of the CSA measurements in the patients with ulnar neuropathy and the controls are presented in Table 2. No statistically significant differences in the CSA of the ulnar nerve at the cubital tunnel were present among the three groups $(P=0.081)$. However, patients with ulnar neuropathy at the cubital tunnel had significantly higher CSA (mean, $13.73 \mathrm{~mm}^{2}$ ) of the ulnar nerve at the cubital tunnel than the control patients (mean, $8.76 \mathrm{~mm}^{2} ; \mathrm{P}=0.002$ ). Statistically significant differences were observed between the patients and the control group with regard to the CSAs at the distal upper arm and proximal forearm. Hypoechogenicity of the ulnar nerve at the cubital tunnel was found in eight patients with ulnar neuropathy, 22 with lateral epicondylitis, and six with medial 
epicondylitis, and no statistically significant difference with regard to this parameter was present among the three groups $(P=0.295)$.

The results of the SWE measurements in the patients with ulnar neuropathy and the controls are presented in Table 3. Statistically significant differences were observed in the SWE values of the ulnar nerve at the cubital tunnel among the three groups $(\mathrm{P}=0.048)$. Patients with ulnar neuropathy at the cubital tunnel had significantly higher SWE values (mean, $66.8 \mathrm{kPa}$ ) for the ulnar nerve at the cubital tunnel (Fig. 2) than controls with medial epicondylitis

Table 1. Demographic data across groups

\begin{tabular}{lcccc}
\hline Diagnosis & $\begin{array}{c}\text { Ulnar } \\
\text { neuropathy } \\
(\mathrm{n}=10)\end{array}$ & $\begin{array}{c}\text { Medial } \\
\text { epicondylitis } \\
(\mathrm{n}=10)\end{array}$ & $\begin{array}{c}\text { Lateral } \\
\text { epicondylitis } \\
(\mathrm{n}=37)\end{array}$ & P-value \\
\hline Sex & & & & 0.024 \\
$\quad$ Male & 7 & 1 & 16 & \\
Female & 3 & 9 & 21 & \\
Age, mean \pm SD (year) & $51.9 \pm 18.8$ & $56.1 \pm 9.8$ & $54.0 \pm 8.8$ & 0.706 \\
Affected side & & & & 0.689 \\
Right & 5 & 6 & 24 & \\
Left & 5 & 4 & 13 & \\
\hline
\end{tabular}

SD, standard deviation. (mean, $21.2 \mathrm{kPa} ; \mathrm{P}=0.015)$ or lateral epicondylitis (mean, 33.9 $\mathrm{kPa} ; \mathrm{P}=0.040$ ). No statistically significant differences were found

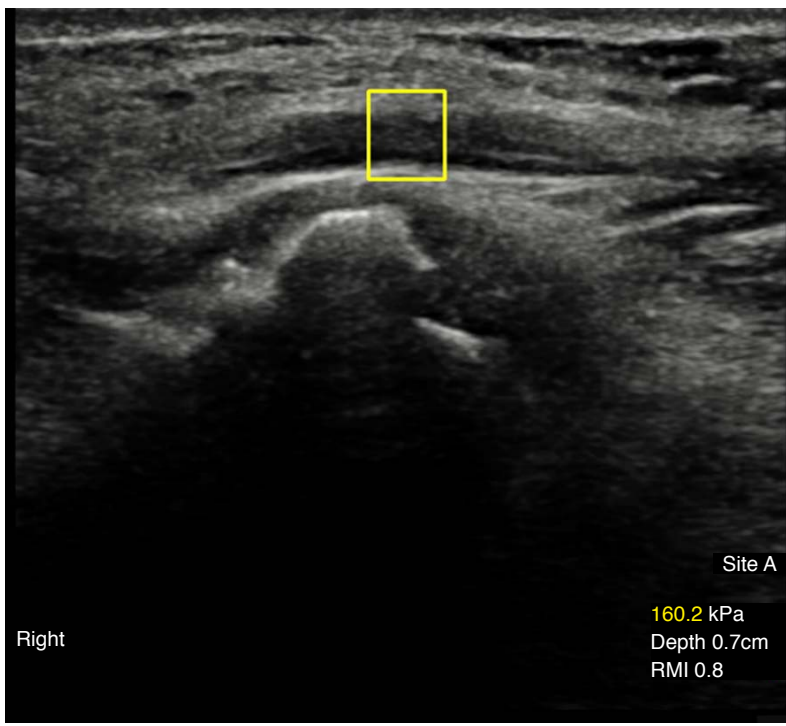

Fig. 2. A 68-year-old man with severe right ulnar neuropathy on electromyography. Elastographic presentation of the ulnar nerve at the level of the cubital tunnel is shown. The shear-wave elastography value of the ulnar nerve at the cubital tunnel was high (160.2 kPa). RMI, reliability measurement index.

Table 2. Mean CSA values by location in ulnar neuropathy, medial epicondylitis, and lateral epicondylitis

\begin{tabular}{lccccc}
\hline \multicolumn{1}{c}{ CSA value } & Ulnar neuropathy & Medial epicondylitis & Lateral epicondylitis & P-value of three groups $\begin{array}{c}\text { P-value of ulnar neuropathy vs. } \\
\text { no ulnar neuropathy }\end{array}$ \\
\hline Proximal CSA $\left(\mathrm{mm}^{2}\right)$ & $8.88 \pm 2.40$ & $5.93 \pm 2.13$ & $5.85 \pm 2.06$ & 0.007 & $<0.001^{\text {a) }}$ \\
Tunnel CSA $\left(\mathrm{mm}^{2}\right)$ & $13.73 \pm 7.24$ & $8.02 \pm 3.78$ & $8.96 \pm 3.51$ & 0.081 & $0.002^{\text {a) }}$ \\
Distal CSA $\left(\mathrm{mm}^{2}\right)$ & $7.49 \pm 3.00$ & $4.85 \pm 1.00$ & $5.61 \pm 2.45$ & 0.094 & $0.038^{\mathrm{b})}$ \\
\hline
\end{tabular}

Values are presented as mean \pm SD.

CSA, cross-sectional area; SD, standard deviation.

${ }^{\text {a) }}$ Statistical analysis was performed using the $t$ test. ${ }^{b}$ Statistical analysis was performed using the Mann-Whitney test.

Table 3. Mean SWE values and RMI by location in ulnar neuropathy, medial epicondylitis, and lateral epicondylitis

\begin{tabular}{|c|c|c|c|c|c|}
\hline SWE value & Ulnar neuropathy & Medial epicondylitis & Lateral epicondylitis & P-value of three groups & $\begin{array}{c}\text { P-value of ulnar neuropathy vs. } \\
\text { no ulnar neuropathy }{ }^{\text {a) }}\end{array}$ \\
\hline Proximal pressure $(\mathrm{kPa})$ & $25.4 \pm 16.6$ & $23.2 \pm 16.9$ & $28.4 \pm 22.3$ & 0.819 & 0.850 \\
\hline RMI & $0.76 \pm 0.16$ & $0.69 \pm 0.14$ & $0.70 \pm 0.19$ & 0.156 & 0.287 \\
\hline Tunnel pressure $(\mathrm{kPa})$ & $66.8 \pm 52.1$ & $21.2 \pm 5.2$ & $33.9 \pm 23.6$ & 0.048 & 0.020 \\
\hline RMI & $0.68 \pm 0.19$ & $0.75 \pm 0.12$ & $0.67 \pm 0.14$ & 0.849 & 0.616 \\
\hline Distal pressure (kPa) & $27.5 \pm 7.2$ & $28.5 \pm 27.3$ & $31.6 \pm 18.1$ & 0.382 & 0.916 \\
\hline RMI & $0.72 \pm 0.18$ & $0.80 \pm 0.12$ & $0.78 \pm 0.13$ & 0.620 & 0.206 \\
\hline Tunnel/proximal pressure & $3.41 \pm 2.76$ & $1.46 \pm 1.08$ & $2.30 \pm 3.31$ & 0.075 & 0.025 \\
\hline Tunnel/distal pressure & $2.57 \pm 2.32$ & $1.12 \pm 0.66$ & $1.35 \pm 1.33$ & 0.072 & 0.022 \\
\hline
\end{tabular}

SWE, shear-wave elastography; RMI, reliability measurement index.

${ }^{\text {a) }}$ Statistical analysis was performed using the Mann-Whitney test. 
between patients and controls with regard to ulnar nerve stiffness at the distal upper arm or the proximal forearm. In addition, the ratios of tunnel pressure to proximal pressure and tunnel pressure to distal pressure in the patients with ulnar neuropathy were higher than in the controls ( $P=0.025$ and $P=0.022$, respectively). The Pearson correlation coefficient between the CSA and SWE values indicated a weak positive relationship $(r=0.143)$, but this relationship was not statistically significant $(\mathrm{P}=0.290)$.

An ROC curve illustrating the diagnostic accuracy of SWE (Fig. 3) demonstrated an AUC value of $0.736(95 \% \mathrm{Cl}, 0.560$ to 0.912$)$. An ulnar nerve stiffness value of $33.5 \mathrm{kPa}$ provided $70.2 \%$ specificity, 80.0\% sensitivity, 36.4\% PPV, and 94.3\% NPV for the differentiation between ulnar neuropathy and other diseases. In addition, an ulnar nerve SWE value of $31.0 \mathrm{kPa}$ provided $100 \%$ specificity, $80.0 \%$ sensitivity, 100\% PPV, and $83.3 \%$ NPV for the differentiation between ulnar neuropathy and medial epicondylitis. ROC curves representing the diagnostic accuracy of the SWE ratios of tunnel pressure to proximal pressure and tunnel pressure to distal pressure in ulnar neuropathy exhibited AUC values of $0.728(95 \% \mathrm{Cl}, 0.551$ to 0.904$)$ and $0.732(95 \% \mathrm{Cl}, 0.555$ to 0.909$)$, respectively (Fig. $3)$. The cut-off ratios of tunnel pressure to proximal pressure and tunnel pressure to distal pressure with $70.0 \%$ sensitivity and $74.5 \%$ specificity were 2.1 and 1.7 , respectively. In contrast, an ROC curve of the diagnostic accuracy of CSA measurement had an AUC value of $0.713(95 \% \mathrm{Cl}, 0.541$ to 0.885$)$. A CSA value of 10.0 $\mathrm{mm}^{2}$ provided $60.0 \%$ sensitivity, $68.1 \%$ specificity, $30.0 \% \mathrm{PPV}$, and $89.2 \%$ NPV for the differentiation between ulnar neuropathy and other diseases.

\section{Discussion}

In this study, patients with ulnar neuropathy at the cubital tunnel (mean, $13.73 \mathrm{~mm}^{2}$ and $66.8 \mathrm{kPa}$ ) presented with greater CSA and

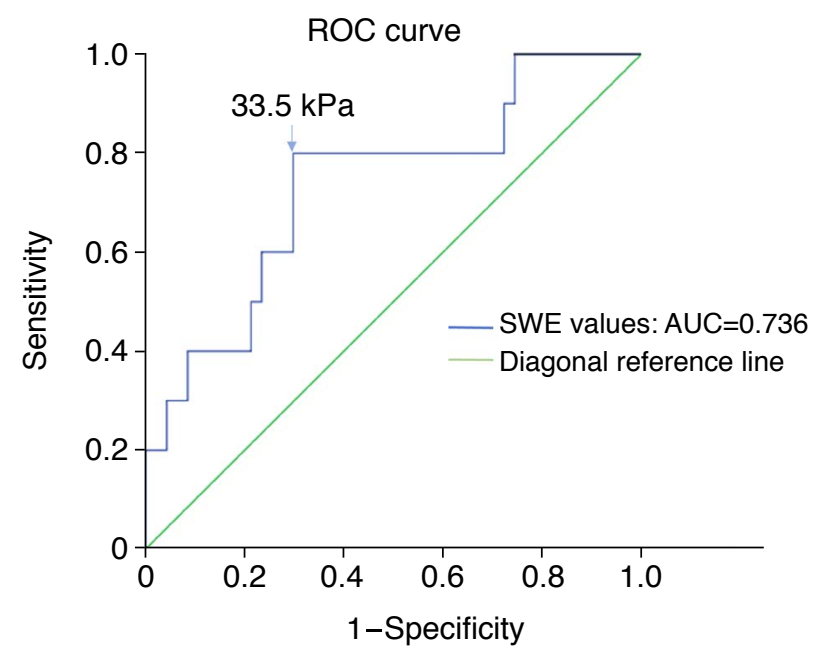

A

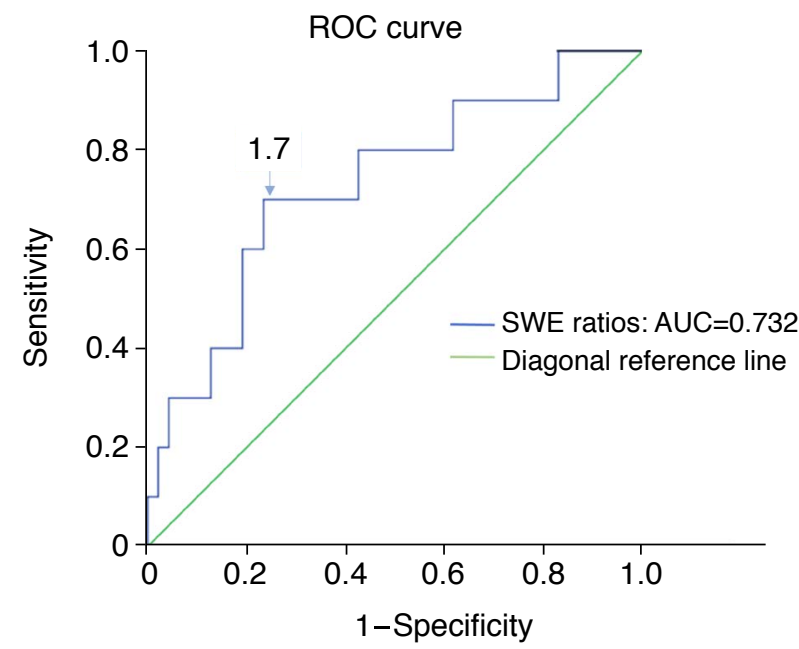

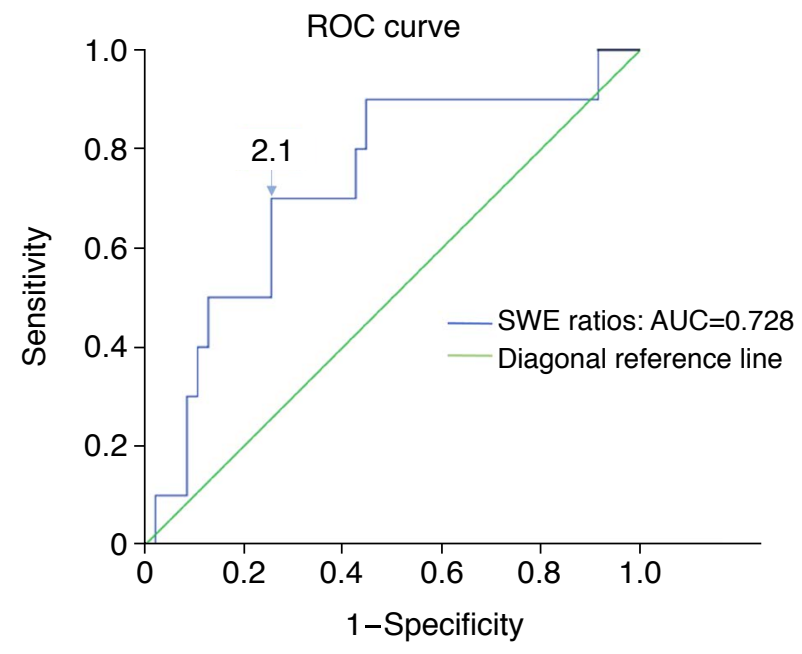

Fig. 3. Receiver operating characteristic (ROC) curves for the diagnostic accuracy of shear-wave elastography (SWE) values for the ulnar nerve at the cubital tunnel (A), SWE ratios of cubital tunnel to proximal pressure (B) and cubital tunnel to distal pressure of the ulnar nerve (C) in the detection of ulnar neuropathy.

A. The area under the ROC curve (AUC) for the SWE value for the ulnar nerve at the cubital tunnel was $0.736(95 \%$ confidence interval [Cl], 0.560 to 0.912 ). B. The AUC value of the ratio of cubital tunnel to the proximal pressure of the ulnar nerve was $0.728(95 \% \mathrm{Cl}, 0.551$ to 0.904$)$. C. The AUC value of the ratio of the cubital tunnel to the distal pressure of the ulnar nerve was $0.732(95 \% \mathrm{Cl}, 0.555$ to 0.909$)$. 
SWE values of the ulnar nerve at the cubital tunnel than control participants with medial epicondylitis or lateral epicondylitis. Using ROC analysis, the cut-off range for SWE-determined ulnar neuropathy was found to be 31.0 to $33.5 \mathrm{kPa}$, which provided optimal accuracy and showed comparable diagnostic performance to the CSA value.

The diagnosis of ulnar neuropathy is based primarily on medical history, physical examination, and an electrodiagnostic study, the last of which is traditionally used for confirmation. However, electrodiagnostic studies have a sensitivity of $37 \%-86 \%$ [16] and are time-consuming and invasive procedures. Therefore, ultrasound imaging may be helpful as an alternative or complementary study in the diagnosis of compressive neuropathy. On B-mode ultrasound images, compressive neuropathy can be diagnosed based on the typical morphological features of compressive neuropathy, including hypoechoic thickening proximal to the compression site, loss of the normal fascicular pattern, and perineural soft tissue edema. Several quantitative ultrasound studies for the diagnosis of neuropathy have been conducted with a focus on CSA measurements [17-19]. These studies have suggested that reference CSA values for the ulnar nerve at the cubital tunnel range from 6 to $9 \mathrm{~mm}^{2}$, and the frequentlyused cut-off value is $10 \mathrm{~mm}^{2}$, which has been found to have a broad range of sensitivity ranging from $24.5 \%$ to $80 \%$ [17]. Our results were similar to the previous findings. In the present study, the cutoff value of CSA was $10.0 \mathrm{~mm}^{2}$, and this cut-off value provided $68.1 \%$ specificity and $60.0 \%$ sensitivity for the differentiation between ulnar neuropathy and other diseases.

SWE is an advanced quantitative ultrasound technique that can be used to evaluate soft tissue elasticity. In compressive neuropathy, a higher pressure within the canal could cause ischemia, edema, inflammation, and finally fibrosis in the intraneural space and the synovium [20]. All of these changes to the compressed nerve may result in increased nerve stiffness. Therefore, SWE could be a valuable complement in the diagnosis of compressive neuropathy. Some studies have been conducted to analyze the potential application of elastography in the assessment of compressive neuropathies such as carpal tunnel syndrome, ulnar tunnel syndrome, and cubital tunnel syndrome [13,21-24]. Most of these evaluations of compressive neuropathies have been focused on carpal tunnel syndrome. One article demonstrated a clinical application of elastography in cases of cubital tunnel syndrome, with a mean SWE value of $96.38 \mathrm{kPa}$ for patients with cubital tunnel syndrome and a mean value of $33.08 \mathrm{kPa}$ for healthy control participants [13]. In comparison, our study showed that the mean SWE value of patients with cubital tunnel syndrome was $66.8 \mathrm{kPa}$, while those of controls with medial epicondylitis or lateral epicondylitis were $21.2 \mathrm{kPa}$ and $33.9 \mathrm{kPa}$, respectively. Our results for the control groups were thus similar to the result of the previous study, while the mean SWE values and diagnostic cut-off SWE value of the cubital tunnel syndrome group in our study were lower than previously found. Our study suggested that SWE values of $33.5 \mathrm{kPa}$ provided $70.2 \%$ specificity and $80.0 \%$ sensitivity for the differentiation between ulnar neuropathy and other diseases, and this diagnostic performance of SWE was higher than that of CSA on B-mode images. Paluch et al. [13] suggested a cut-off value for ulnar neuropathy of $61 \mathrm{kPa}$, while Dikici et al. [12] suggested a value for tibial nerve diabetic neuropathy of 51 $\mathrm{kPa}$. Our results may have been affected by the disease severity and duration, the patients' body mass index, or the small number of patients. Moreover, Cingoz et al. [24] and Dikici et al. [12] have suggested that the severity of neuropathy is correlated with SWE values. Our study included only patients who underwent an initial ultrasound, most of whom could be estimated to have had mild neuropathy. Moreover, the use of an automatically determined ROI setting could have influenced the low cut-off SWE value of ulnar neuropathy in our study because this ROI included the ulnar nerve and some perineural soft tissue. Our cut-off SWE value of the ulnar nerve could represent the upper normal limit of ulnar nerve stiffness. Our control results showed that the mean SWE value of the medial epicondylitis group was slightly lower than that of the lateral epicondylitis group. Although no statistically significant difference was observed between these mean SWE values, and the number of patients with medial epicondylitis is small, this finding could suggest that it is unusual for medial epicondylitis to cause structural changes of the cubital tunnel and compression of the ulnar nerve. In our study, the mean SWE value at the proximal level to the cubital tunnel was lower than that at the cubital tunnel, and this result aligns with previous findings [13]. The ratios of tunnel pressure to proximal pressure and tunnel pressure to distal pressure in patients with ulnar neuropathy were higher than in the controls, and the diagnostic performances of these ratios were similar to those of SWE of the ulnar nerve at the cubital tunnel. In addition, these cutoff values for the ratios of tunnel pressure to proximal pressure and tunnel pressure to distal pressure were similar to the ratios of canal pressure to proximal pressure found in previous studies $[13,21]$. These ratios may present adjusted values that account for patientspecific and machine-specific factors that impact SWE readings.

In this study, eight patients were excluded due to low RMI values, and these patients had clinical findings of low body mass index, inflammatory changes indicative of calcific tendinitis at the common flexor tendon, and a high signal intensity of the ulnar nerve on magnetic resonance imaging without the symptoms of ulnar neuropathy. In general, relative to strain elastography, SWE is considered to be an easier way to obtain objective and reproducible measurements of direct tissue elasticity because of the lack of 
need for manual compression. However, this could suggest that the reliability of SWE values is influenced by the nature of the adjacent soft tissue.

This study had some limitations, the most critical of which was its small sample size. Our results showed diagnostic accuracy for cubital tunnel syndrome, which was confirmed with clinical symptoms and electrodiagnostic testing used as a reference standard. However, electrodiagnostic testing has been reported to have low sensitivity. It is possible that we failed to include patients with cubital tunnel syndrome whose findings were negative at the time of electrodiagnostic testing. Additionally, the ROI of the SWE measurement of this ultrasonography equipment was preset for easy and simple manipulation, and our SWE measurements may have included the ulnar nerve and the adjacent soft tissue. Our study did not include an assessment of the interobserver agreement for the SWE measurement of the ulnar nerve. Therefore, longitudinal studies are needed to show the progressive changes in nerve stiffness, especially with regard to treatment.

In conclusion, the ulnar nerve is stiffer in patients with cubital tunnel syndrome than in patients with lateral or medial epicondylitis. In addition, SWE seems to be a new reliable and simple quantitative diagnostic technique to aid in the precise diagnosis of ulnar neuropathy at the cubital tunnel.

ORCID: Sujin Kim: https://orcid.org/0000-0003-2011-0752; Guen Young Lee: https:// orcid.org/0000-0002-6906-5182

\section{Author Contributions}

Conceptualization: Lee GY, Kim S. Data acquisition: Lee GY, Kim S. Data analysis or interpretation: Kim S. Drafting of the manuscript: Lee GY, Kim S. Critical revision of the manuscript: Lee GY. Approval of the final version of the manuscript: all authors.

\section{Conflict of Interest}

This study was performed using a Samsung RS85 ultrasonography device demonstrated by DongKook Life Science. Co., Ltd., Republic of Korea.

\section{Acknowledgments}

This study was supported by the Chung-Ang University Research Grants in 2020.

\section{References}

1. Assmus $H$, Antoniadis G, Bischoff $C$, Hoffmann R, Martini $A K$, Preissler $P$, et al. Cubital tunnel syndrome: a review and management guidelines. Cent Eur Neurosurg 2011;72:90-98.

2. Carter GT, Weiss MD, Friedman AS, Allan CH, Robinson L. Diagnosis and treatment of work-related ulnar neuropathy at the elbow. Phys Med Rehabil Clin N Am 2015;26:513-522.

3. Mowlavi A, Andrews K, Lille S, Verhulst S, Zook EG, Milner S. The management of cubital tunnel syndrome: a meta-analysis of clinical studies. Plast Reconstr Surg 2000;106:327-334.

4. Wiesler ER, Chloros GD, Cartwright MS, Shin HW, Walker FO. Ultrasound in the diagnosis of ulnar neuropathy at the cubital tunnel. J Hand Surg Am 2006;31:1088-1093.

5. Gechev A, Kane NM, Koltzenburg M, Rao DG, van der Star R. Potential risks of iatrogenic complications of nerve conduction studies (NCS) and electromyography (EMG). Clin Neurophysiol Pract 2016;1:62-66.

6. Choi SJ, Ahn JH, Ryu DS, Kang CH, Jung SM, Park MS, et al. Ultrasonography for nerve compression syndromes of the upper extremity. Ultrasonography 2015;34:275-291.

7. Lima K, Costa Junior JFS, Pereira WCA, Oliveira LF. Assessment of the mechanical properties of the muscle-tendon unit by supersonic shear wave imaging elastography: a review. Ultrasonography 2018:37:3-15.

8. Yoo SJ, Lee S, Song Y, Kim CK, Lee BG, Bae J. Elasticity of torn supraspinatus tendons measured by shear wave elastography: a potential surrogate marker of chronicity? Ultrasonography 2020:39:144-151.

9. Nichols CW, Brismee JM, Hooper TL, Bertrand-Grenier A, Gilbert KK, St-Pierre MO, et al. Glenohumeral joint capsular tissue tension loading correlates moderately with shear wave elastography: a cadaveric investigation. Ultrasonography 2020;39:114-120.

10. Yeoh HJ, Kim TY, Ryu JA. The feasibility of shear wave elastography for diagnosing superficial benign soft tissue masses. Ultrasonography 2019;38:37-43.

11. Andrade RJ, Nordez A, Hug F, Ates F, Coppieters MW, PezaratCorreia $P$, et al. Non-invasive assessment of sciatic nerve stiffness during human ankle motion using ultrasound shear wave elastography. J Biomech 2016;49:326-331.

12. Dikici AS, Ustabasioglu FE, Delil $S$, Nalbantoglu M, Korkmaz B, Bakan $S$, et al. Evaluation of the tibial nerve with shear-wave elastography: a potential sonographic method for the diagnosis of diabetic peripheral neuropathy. Radiology 2017;282:494-501.

13. Paluch L, Noszczyk B, Nitek Z, Walecki J, Osiak K, Pietruski P. Shearwave elastography: a new potential method to diagnose ulnar neuropathy at the elbow. Eur Radiol 2018;28:4932-4939.

14. He Y, Xiang X, Zhu BH, Qiu L. Shear wave elastography evaluation of the median and tibial nerve in diabetic peripheral neuropathy. Quant Imaging Med Surg 2019;9:273-282.

15. Kantarci F, Ustabasioglu FE, Delil S, Olgun DC, Korkmazer B, Dikici $A S$, et al. Median nerve stiffness measurement by shear wave elastography: a potential sonographic method in the diagnosis of 
carpal tunnel syndrome. Eur Radiol 2014;24:434-440.

16. Rayegani SM, Raeissadat SA, Kargozar E, Rahimi-Dehgolan S, Loni E. Diagnostic value of ultrasonography versus electrodiagnosis in ulnar neuropathy. Med Devices (Auckl) 2019;12:81-88.

17. Chang KV, Wu WT, Han DS, Ozcakar L. Ulnar nerve cross-sectional area for the diagnosis of cubital tunnel syndrome: a meta-analysis of ultrasonographic measurements. Arch Phys Med Rehabil 2018;99:743-757.

18. Ayromlou H, Tarzamni MK, Daghighi MH, Pezeshki MZ, Yazdchi M, Sadeghi-Hokmabadi E, et al. Diagnostic value of ultrasonography and magnetic resonance imaging in ulnar neuropathy at the elbow. ISRN Neurol 2012;2012:491892.

19. Kim JH, Won SJ, Rhee WI, Park HJ, Hong HM. Diagnostic cutoff value for ultrasonography in the ulnar neuropathy at the elbow. Ann Rehabil Med 2015;39:170-175.

20. Rempel DM, Diao E. Entrapment neuropathies: pathophysiology and pathogenesis. J Electromyogr Kinesiol 2004;14:71-75.

21. Paluch L, Noszczyk BH, Walecki J, Osiak K, Kicinski M, Pietruski P. Shear-wave elastography in the diagnosis of ulnar tunnel syndrome. J Plast Reconstr Aesthet Surg 2018;71:1593-1599.

22. Martin MJ, Cartwright MS. A pilot study of strain elastography in the diagnosis of carpal tunnel syndrome. J Clin Neurophysiol 2017;34:114-118.

23. Miyamoto H, Halpern EJ, Kastlunger M, Gabl M, Arora R, BellmannWeiler $\mathrm{R}$, et al. Carpal tunnel syndrome: diagnosis by means of median nerve elasticity: improved diagnostic accuracy of US with sonoelastography. Radiology 2014;270:481-486.

24. Cingoz M, Kandemirli SG, Alis DC, Samanci C, Kandemirli GC, Adatepe NU. Evaluation of median nerve by shear wave elastography and diffusion tensor imaging in carpal tunnel syndrome. Eur J Radiol 2018;101:59-64. 